\title{
||||||||||||||||||||||||||||||||||||||||||||||||||||||||||||||||||.
}

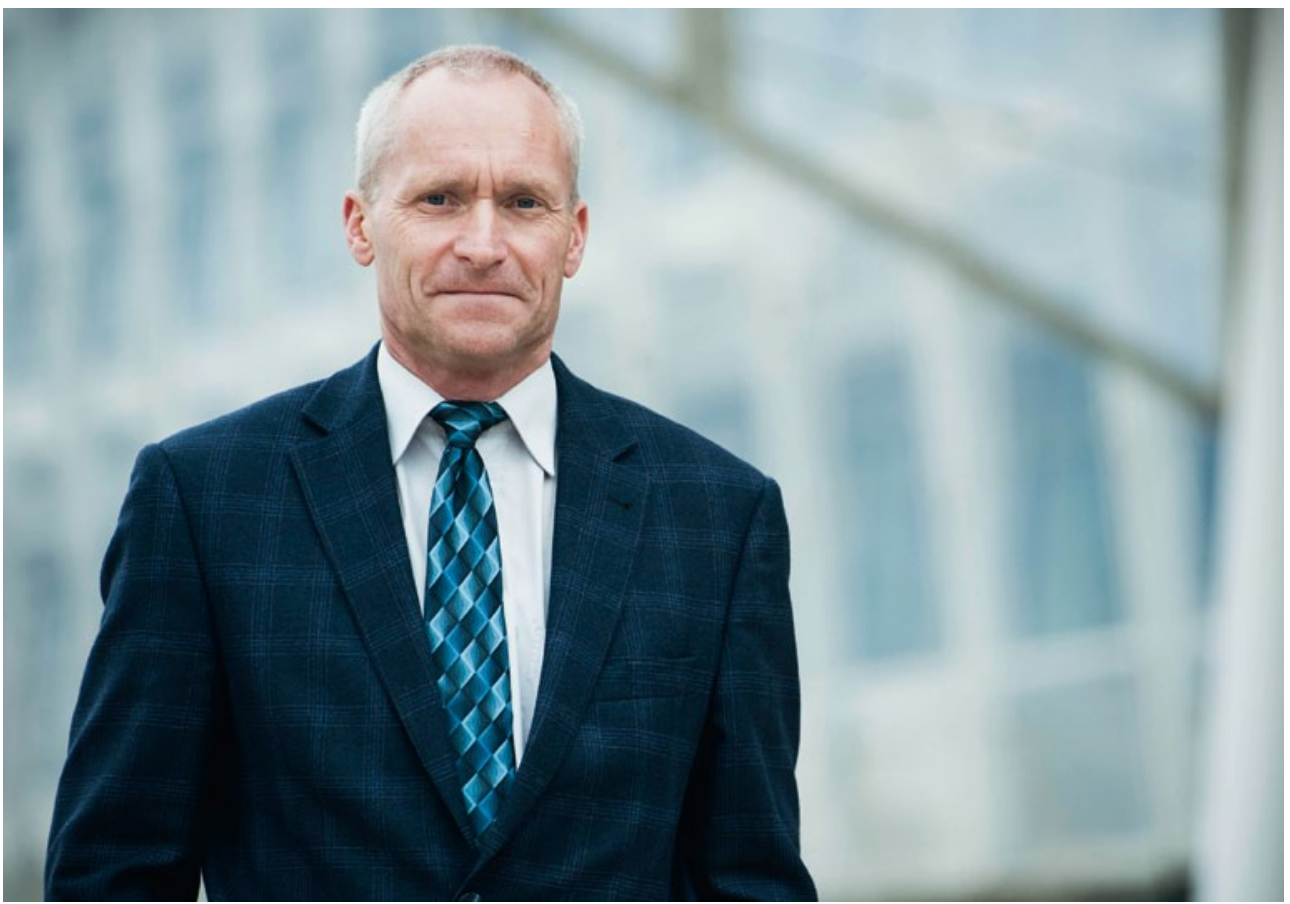

DR.-ING. UWE MEINIG

Leiter Entwicklung neue

Motor- und Getriebekomponenten, SHW Automotive

\section{EINFACHE UND INTELLIGENTE LÖSUNGEN}

Die Technik des Pkw und mit ihr die Technik des Verbrennungsmotors haben in den vergangenen drei Jahrzehnten eine beeindruckende Entwicklung durchlaufen. $\mathrm{Zu}$ diesen Innovationen zählen bezüglich der Antriebe die zahlreichen, auf breiter Basis eingeführten technischen Schritte zur Reduzierung der Schadstoffemissionen bei gleichzeitiger Verringerung der Kraftstoffverbräuche, wie Abgaskatalysatoren, Abgasrückführung, Saugrohrund Direkteinspritzung, variable Ventiltriebe, mechanische und Abgasturboaufladung, Partikelfilter, aber auch der Einsatz verbesserter Getriebe. Vergleichbare Innovationen wurden fahrzeugseitig beispielsweise auf dem Gebiet der aktiven und passiven Sicherheit umgesetzt. So sehr diese Entwicklung aus ökologischer Sicht und unter Sicherheitsgesichtspunkten zu begrüßen ist, so hat sie auch die Kosten und Komplexität der Fahrzeuge gesteigert. Mit der derzeit politisch forcierten Entwicklung und Einführung von Hybrid- und Elektrofahrzeugen ist ein weiterer Anstieg der Komplexität der Fahrzeuge absehbar. Gemäß der Theorie der technischen Zuverlässigkeit steigt unter der Voraussetzung gleicher Qualitätsstandards die Ausfallwahrscheinlichkeit exponential mit der Zahl der miteinander verketteten Einzelkomponenten und -systeme. Bei einem Teil der Automobilkunden ist bereits heute - nicht nur begründet durch eine begrenzte Kaufkraft - eine gewisse Verweigerungshaltung gegenüber allzu komplexen Produkten erkennbar. Weitere Argumente für einfachere Produkte in der Modellpalette der Hersteller sind die Förderung einer Markenbindung bei im Allgemeinen weniger kaufkräftigen Fahreinsteigern, aber auch absehbare Kundenreflexe in Krisenzeiten. Unter diesen Gesichtspunkten scheint die heimische Automobilindustrie gut beraten, auch Fahrzeuge anzubieten, die, trotz einer auf das zwingend erforderliche Maß begrenzten Komplexität, eine im Hinblick auf die Kosten-NutzenRelation und damit den Kundennutzen, aber auch Design und Image, attraktive Lösungen bilden.

Die Analyse heimischer Branchen, die in der Vergangenheit unter massiven Wettbewerbsdruck geraten sind, offenbart vielfach eine Tendenz der Hersteller, sich in die Nische beziehungsweise in das Premiumsegment zurückzuziehen. Diese Strategie hat sich jedoch allzu oft als Einstieg in den Ausstieg erwiesen, da mit der Aufgabe der Großserienproduktionsstrukturen schrittweise auch die Basis für die wirtschaftliche Entwicklung und Produktion von Produkten im Hochpreissegment geschwunden ist.

Die Fähigkeit europäischer Automobilhersteller neben dem Premiumsegment trotz heimischer Kostenstrukturen, basierend auf intelligenten Produktansätzen und konsequenter Entwicklung und Optimierung sämtlicher Entwicklungs- und Produktionsprozesse, auch mit einfachen, weniger komplexen Lösungen im internationalen Wettbewerb ertragreich zu produzieren, lässt sich dabei als ein wesentlicher Indikator für die Zukunftsfähigkeit einer Branche betrachten. Wie in anderen Bereichen des Lebens gelte auch hier der Leitspruch: Das eine tun, aber das andere nicht lassen ... 